\title{
Stakeholder views regarding patient discharge from intensive care: Suboptimal quality and opportunities for improvement
}

\author{
Pin Li MD MSc ${ }^{1,2 *}$, Jamie M Boyd BA ${ }^{3 *}$, William A Ghali MD MPH ${ }^{1,2,3}$, Henry T Stelfox MD PhD ${ }^{1,2,3,4}$
}

P Li, JM Boyd, WA Ghali, HT Stelfox. Stakeholder views regarding patient discharge from intensive care: Suboptimal quality and opportunities for improvement. Can Respir J 2015;22(2):109-118.

OBJECTIVE: To provide the first description of intensive care unit (ICU) discharge practices from the perspective of Canadian ICU administrators, and ICU providers from Canada, the United States and the United Kingdom.

METHODS: The authors identified 140 Canadian ICUs and administered a survey to ICU administrators (unit manager, director) to obtain an institutional perspective. Also surveyed were members of professional critical care associations in Canada, the United States and the United Kingdom, using membership distribution lists, to obtain a provider perspective.

RESULTS: A total of 118 ICU administrators (114 ICUs [81\%]) and 737 ICU providers (denominator unknown) responded to the survey. Administrator and provider respondents reported that ICU physicians are primarily responsible for determining the timing $(70 \%$ and $77 \%$, respectively) and safety (94\% and $96 \%$ ) for patients discharged from ICU. The majority of respondents indicated that patient summaries ( $87 \%$ and $85 \%$ ) and medication reconciliation $(78 \%$ and $79 \%)$ were part of their institutions' discharge process. One-half of respondents reported the use of discharge protocols, while a minority indicated that checklists $(46 \%$ and $44 \%$ ), electronic tools (19\% and $28 \%$ ) or outreach follow-up (44\% and $33 \%$ ) were used. The majority of respondents rated current ICU discharge practices to be of medium quality $(57 \%$ and $58 \%$ scored 3 on a five-point scale). Suggested opportunities for improvement included the information provided to patients and families ( $71 \%$ and $59 \%)$ and collaboration among hospital units $(65 \%$ and $66 \%)$.

CONCLUSION: Findings from the present study revealed the complexity of the ICU discharge process, considerable practice variation, perception of only medium quality and several proposed opportunities for improvement.

Key Words: Critical care; Intensive care; Patient discharge; Transitions of care
Le point de vue des intervenants sur le congé des patients de l'unité de soins intensifs : une qualité sous-optimale et des possibilités d'amélioration

OBJECTIF : Fournir la première description des pratiques de congé de l'unité de soins intensifs (USI) d'après les administrateurs canadiens d'USI et les dispensateurs de soins à l'USI du Canada, des États-Unis et du Royaume-Uni. MÉTHODOLOGIE : Les auteurs ont repéré 140 USI canadiennes et distribué un sondage à leurs administrateurs (gestionnaire d'unité, directeur) pour obtenir le point de vue de l'établissement. Ils ont également sondé les membres d'associations professionnelles de soins intensifs du Canada, des États-Unis et du Royaume-Uni à l'aide de listes des membres, afin d'obtenir le point de vue des dispensateurs de soins.

RÉSULTATS : Au total, 118 administrateurs d'USI (114 USI [81 \%]) et 737 dispensateurs de soins à l'USI (dénominateur inconnu) ont répondu au sondage. Les répondants administrateurs et dispensateurs ont déclaré que les médecins de l'USI sont les principaux responsables de déterminer le moment (70\% et $77 \%$, respectivement) et la sécurité (94\% et $96 \%$ ) à l'égard des patients qui obtiennent leur congé de l'USI. La majorité des répondants ont indiqué que les résumés des patients ( $87 \%$ et $85 \%$ ) et le bilan comparatif des médicaments ( $78 \%$ et $79 \%$ ) faisaient partie du processus de congé de leur établissement. La moitié des répondants a déclaré utiliser des protocoles de congé, tandis qu'une minorité a précisé que des listes de vérification ( $46 \%$ et $44 \%$ ), des outils électroniques ( $19 \%$ et $28 \%$ ) ou un suivi après le congé ( $44 \%$ et $33 \%$ ) étaient privilégiés. La majorité des répondants trouvaient les pratiques de congé de l'USI en cours de qualité moyenne (57 \% et $58 \%$, résultat de trois sur une échelle de cinq). Les possibilités d'amélioration suggérées incluaient l'information transmise aux patients et aux familles (71\% et $59 \%$ ) et la collaboration entre unités hospitalières ( $65 \%$ et $66 \%$ ).

CONCLUSION : Les observations de la présente étude ont révélé la complexité du processus de congé de l'USI, d'importantes variations des pratiques, une perception de qualité moyenne seulement et plusieurs propositions d'amélioration.

Discharge from the ICU should ensure that patients are discharged using a process that optimizes patient care and reduces the risk of adverse events including hospital mortality. However, there is no consensus on an ideal ICU discharge model (16), and there appears to be important variation in the morbidity and mortality of discharged patients (17-19). Given the challenges associated with ICU discharge and limited available literature describing current discharge practices, we conducted a survey in three countries as an essential first step toward identifying opportunities for improvement. We surveyed ICU administrators (unit manager, director) for an institutional perspective and members of professional care associations for an ICU provider perspective. Our objectives were to understand the organization of ICU discharge; explore stakeholder needs and expectations surrounding ICU discharge; and determine stakeholder perceptions of quality of care during ICU discharge and opportunities for improvement. associated with poor communication (13) and poor medication reconciliation (accurate and complete transfer of medication information at interfaces of care) $(7,14,15)$.

*Co-first authors, both of whom contributed equally to the work

${ }^{1}$ Department of Medicine, University of Calgary and Alberta Health Services - Calgary Zone; ${ }^{2}$ Institute for Public Health; ${ }^{3}$ Department of Community Health Sciences, University of Calgary; ${ }^{4}$ Department of Critical Care Medicine, University of Calgary and Alberta Health Services - Calgary Zone, Calgary, Alberta

Correspondence: Dr Henry T Stelfox, Teaching Research $\mathcal{E}$ Wellness Building, University of Calgary, 3280 Hospital Drive Northwest, Calgary, Alberta T2N 4Z6. Telephone 403-944-2334, fax 403-283-9994, e-mail tstelfox@ucalgary.ca 


\section{METHODS}

\section{Study questions}

ICU administrators and providers were queried about their experiences and perceptions of ICU discharge. Stakeholders were asked three specific questions:

1. How patient discharge from ICU is performed (structure, process) at their institution?

2. How is information provided to patients and families on discharge from ICU?

3. What is the quality of care during patient discharge from ICU and how can it be improved?

\section{Study participants}

Canadian ICUs were identified by reviewing Internet resources and government health sites, and contacting university medical schools and affiliated hospitals. 'ICU' was defined as a distinct hospital specialty care unit staffed by specialized professionals where immediate and continuous life-sustaining treatment (minimum capabilities include invasive monitoring, vasoactive medications and mechanical ventilation) is provided to patients who have life-threatening conditions regardless of subspecialty (20). Step-down units were excluded. Key informants (medical director, unit manager) were identified from a search of their hospitals' websites, contacts of the project team and local telephone directories. To obtain an ICU provider perspective, members of professional critical care associations in Canada, the United States (US) and the United Kingdom (UK) were surveyed using membership distribution lists from the Canadian Association of Critical Care Nursing (CACCN) (21), Society for Critical Care Medicine (SCCM) (22) and the Intensive Care Society (ICS) (23). These professional critical care associations were selected because their membership primarily comprises ICU providers working in health care systems with advanced critical care capacities, and the associations had protocols for posting links to electronic surveys on association newsletters and websites.

\section{Survey design and testing}

Items for the survey instrument were generated based on a structured literature review. To identify relevant articles, the Medline, EMBASE, CINAHL and the Cochrane Central Register of Controlled Trials databases were searched using a combination of the following terms: "critical care", "intensive care", "discharge plan", "transfer process", "patient discharge" and "patient transfer". The survey was designed to obtain basic information about ICU organizational characteristics (12 questions), current discharge practices (11 questions), communication with patients and families during discharge (three questions) and the quality of ICU discharge and opportunities for improvement (seven questions). The survey underwent an iterative development process (24). Members of the research team serially reviewed the instrument, eliminating redundant items and revising retained items. The survey was then pilot tested with three ICU managers and providers from local ICU facilities to evaluate the clinical sensibility of the revised items and further modified based on their suggestions. The final survey was comprised of 31 close-ended questions and two openended questions, and was documented to take less than $10 \mathrm{~min}$ to complete (Appendixes 1 and 2).

\section{Survey administration}

ICU administrators: Survey distribution began February 23, 2012. The survey was mailed to the medical director or unit manager identified for each Canadian ICU. Return postage was included. If the initial survey was not returned, up to two follow-up mail surveys were sent, followed by an e-mail reminder (when available) in three-week intervals.

ICU providers: Professional associations provided resources and protocols for distribution of surveys to members in Canada, the US and the UK. A descriptive paragraph and link to the electronic survey was included in three newsletter e-mails sent to members of CACCN (Canada) and the link was also included on the associations' website.
SCCM (US) members received the link in two newsletter e-mails. ICS members (UK) were able to access the link through the associations' website. Survey distribution began in February 2012 and closed July 31, 2012.

\section{Statistical analysis}

The strategy for the primary analysis was to describe ICU discharge practices by answering each of the three specific study questions. Survey responses were summarized using nominal (proportions) and ordinal (median and interquartile range $[\mathrm{IQR}]$ ) measures. Formal hypothesis testing was not performed. Using the same descriptive measures used for the primary analysis, four prespecified subgroup analyses were performed according to ICU education status (teaching versus nonteaching), location (urban versus rural), unit size (number of funded beds) and perceived quality of discharge (low versus medium versus high). Summary statistics were calculated using SPSS version 17.0 (IBM Corporation, USA) (25). Ethics approval was obtained from the Conjoint Health Research Ethics Board at the University of Calgary, Calgary, Alberta.

\section{Survey response}

\section{RESULTS}

Between February 2012 and July 2012, the survey was sent to 140 ICU administrators, of which 118 (representing 114 ICUs) (81\%) responded. During the same time period, a total of $737 \mathrm{ICU}$ providers from critical care professional associations in Canada $(n=311)$, the US $(n=276)$, the UK $(n=90)$ and other countries $(n=60)$ responded (denominator unknown becasuse the survey link was posted on association newsletters and websites and association memberships were not disclosed).

\section{Respondent characteristics}

The characteristics of the respondents and their ICU facilities are summarized in Table 1. Respondents to the ICU administrator survey self-identified primarily as managers (eg, unit manager, patient care manager) who worked at teaching hospitals and in ICUs that served medical and surgical patient populations, with a nurse-to-patient ratio of $1: 1$ or $1: 2$. Respondents to the ICU provider survey self-identified primarily as nurses or physicians who similarly primarily worked at teaching hospitals and in ICUs that served surgical and medical patient populations. The majority of ICU administrators and ICU providers reported that their facility discharged $\geq 10$ patients per week.

\section{How ICU discharge is performed}

Table 2 summarizes the reported ICU discharge structures and processes. Both ICU administrators and ICU providers reported that ICU physicians were the primary responsible physician for decisions regarding patient discharge including assessing patient safety for discharge ( $94 \%$ and $96 \%$, respectively); ensuring the receiving service has all pertinent patient information (92\% and $87 \%$ ); and deciding the appropriate service to receive the discharged patient ( $81 \%$ and $87 \%$ ). One-half (52\%) of ICU administrators and ICU providers (51\%) reported the use of a standardized ICU discharge protocol at their facility. Formal communication (using a systematic approach such as sequentially proceeding by systems or problems, in contrast to informal, unstructured communication) between nurses ( $84 \%$ and $88 \%$ ) was reported to be more common than between physicians (60\% and 55\%) during patient discharge. Telephone was reported as the most frequently used mode for discharge communication (70\% and $74 \%$ ).

\section{How information is provided to patients and families on discharge} from the ICU

Table 3 summarizes respondents' impressions of the modes of communication used with patients and family members for ICU discharge. Verbal communication of discharge information was perceived to be the most common mode of provider-patient communication by ICU administrators (99\%) and ICU providers (95\%). A minority reported 
TABLE 1

Characteristics of survey participants*

\begin{tabular}{|c|c|c|}
\hline \multirow[b]{2}{*}{ Characteristics } & \multicolumn{2}{|c|}{ Intensive care unit (ICU) } \\
\hline & $\begin{array}{c}\text { Administrators } \\
(n=118)\end{array}$ & $\begin{array}{l}\text { Providers } \\
(n=737)\end{array}$ \\
\hline \multicolumn{3}{|l|}{ Role within ICU } \\
\hline Manager & $98(83.1)$ & $38(5.4)$ \\
\hline Nurse & $14(11.9)$ & $292(41.8)$ \\
\hline Director & $5(4.2)$ & $110(15.8)$ \\
\hline Physician & $1(0.8)$ & $258(37.0)$ \\
\hline \multicolumn{3}{|l|}{ Academic status } \\
\hline Teaching setting & $91(77.1)$ & $562(76.3)$ \\
\hline Nonteaching setting & $27(22.9)$ & $175(23.7)$ \\
\hline \multicolumn{3}{|l|}{ Geographical location } \\
\hline Urban & $107(90.7)$ & $662(89.8)$ \\
\hline Rural & $11(9.3)$ & $75(10.2)$ \\
\hline \multicolumn{3}{|l|}{ Funded beds } \\
\hline$<10$ & $39(33.6)$ & $121(16.5)$ \\
\hline $10-20$ & $52(44.8)$ & $339(46.1)$ \\
\hline$>20$ & $25(21.6)$ & $275(37.4)$ \\
\hline \multicolumn{3}{|l|}{ Discharges per week, mean } \\
\hline$<10$ & $44(40.7)$ & $145(29.5)$ \\
\hline $10-25$ & $57(52.8)$ & $260(52.8)$ \\
\hline$>25$ & $7(6.5)$ & $87(17.7)$ \\
\hline \multicolumn{3}{|l|}{ Nurse to patient ratio } \\
\hline $1: 1$ or $1: 2$ & $110(93.2)$ & - \\
\hline $1: 3$ or $1: 4$ & $8(6.8)$ & - \\
\hline \multicolumn{3}{|l|}{ Patient populations include: ${ }^{\dagger}$} \\
\hline Medical & $84(71.2)$ & $514(69.7)$ \\
\hline Surgical & $83(70.3)$ & $537(72.9)$ \\
\hline Cardiovascular or cardiac & $51(43.2)$ & $349(47.4)$ \\
\hline Neuroscience & $40(33.9)$ & $338(45.9)$ \\
\hline Trauma & $30(25.4)$ & 307 (41.7) \\
\hline Pediatric & $21(17.8)$ & $127(17.2)$ \\
\hline Neonatal & $11(9.3)$ & $36(4.9)$ \\
\hline Offer ventilation support & $118(100)$ & 735 (99.7) \\
\hline Intensivist-led rounds & $95(82.6)$ & $638(91.7)$ \\
\hline Multidisciplinary rounds (participants include) $)^{\dagger}$ & $99(88.4)$ & $605(87.1)$ \\
\hline Registered nurse & $99(100)$ & $597(98.7)$ \\
\hline Attending physician & $96(97.0)$ & $594(98.2)$ \\
\hline Respiratory therapist & $96(97.0)$ & $506(83.6)$ \\
\hline Pharmacist & $90(90.9)$ & $532(87.9)$ \\
\hline Dietician & $76(76.8)$ & $425(70.2)$ \\
\hline ICU resident & $73(73.7)$ & $460(76.0)$ \\
\hline ICU fellow & $49(49.5)$ & $330(54.5)$ \\
\hline Social worker & $45(45.5)$ & $217(35.9)$ \\
\hline Nurse clinician & $24(24.2)$ & $191(31.6)$ \\
\hline Occupational therapist & $23(23.2)$ & $65(10.7)$ \\
\hline
\end{tabular}

Data presented as $n(\%)$. *Response rates for individual questions varied from $66 \%$ to $100 \%$ (median $100 \%$, interquartile range $95 \%$ to $100 \%$ ); ${ }^{t}$ Responses not mutually exclusive

providing patients and families with written communication before discharge (30\% and 20\%). Very few ICU providers (3\%) reported that no information is provided to patients and families at discharge.

Quality of care during patient discharge from the ICU and opportunities for improvement

More than one-half (62\%) of ICU administrators and ICU providers (51\%) reported the use of quality indicators in their ICU to measure the quality of ICU discharge. Readmission rates ( $<24 \mathrm{~h},<48 \mathrm{~h},<72 \mathrm{~h}$, time not specified) were the most commonly reported quality indicator $(41 \%$ and $39 \%$ ), with the time of discharge (13\% and 5\%), length of stay ( $8 \%$
TABLE 2

Respondents indicating use of various discharge practices*

\begin{tabular}{lcc}
\hline & \multicolumn{2}{c}{ Intensive care unit (ICU) } \\
\cline { 2 - 3 } Discharge practice & $\begin{array}{c}\text { Administrators } \\
(\mathbf{n}=\mathbf{1 1 8})\end{array}$ & $\begin{array}{c}\text { Providers } \\
(\mathbf{n}=\mathbf{7 3 7})\end{array}$ \\
\hline Physician responsible for deciding the time & a patient is discharged \\
ICU MD & $78(69.6)$ & $535(76.9)$ \\
Receiving MD & $21(18.8)$ & $157(22.6)$ \\
Physician responsible for assessing when it is safe to discharge & \\
ICU MD & $106(93.8)$ & $671(96.4)$ \\
Receiving MD & $27(23.9)$ & $191(27.4)$
\end{tabular}

Physician responsible for deciding the appropriate service to receive the discharged patient ${ }^{\dagger}$

ICU MD $91(81.2) \quad 605(86.9)$

Receiving MD 48 (42.9) 339 (48.7)

Physician responsible for ensuring the receiving service has all the pertinent patient information ${ }^{\dagger}$

\begin{tabular}{lrc} 
ICU MD & $105(92.1)$ & $606(87.1)$ \\
Receiving MD & $37(32.5)$ & $213(30.6)$ \\
Structure of discharge communication ${ }^{\dagger}$ & & \\
Formalized RN to RN & $96(83.5)$ & $577(88.4)$ \\
Informal RN to RN & $45(39.1)$ & $219(32.0)$ \\
Formalized MD to MD & $69(60.0)$ & $379(55.4)$ \\
Informal MD to MD & $50(43.5)$ & $334(48.8)$ \\
Mode of provider communication used ${ }^{\dagger \ddagger}$ & & \\
Telephone & $81(70.4)$ & $509(74.2)$ \\
Face to face & $60(52.2)$ & $236(34.4)$ \\
Paper & $58(50.4)$ & $318(46.4)$ \\
Electronic & $7(6.1)$ & $65(9.5)$ \\
Components of ICU discharge ${ }^{\dagger}$ & & \\
Patient summary & $96(86.5)$ & $576(84.6)$ \\
Medication reconciliation & $86(77.5)$ & $535(78.6)$ \\
Standardized ICU discharge protocol & $59(51.8)$ & $347(50.7)$ \\
Standardized discharge checklist & $51(45.9)$ & $296(43.5)$ \\
Electronic discharge tool & $21(18.9)$ & $192(28.2)$ \\
ICU outreach team participates in discharge & $50(43.5)$ & $227(32.6)$ \\
\hline
\end{tabular}

Data presented as $n(\%)$. *Response rates for individual questions varied from $92 \%$ to $100 \%$ (median $94 \%$, interquartile range $94 \%$ to $96 \%$ ); ${ }^{\dagger}$ Responses not mutually exclusive; $¥$ Data represent respondents who reported using this mode of communication very frequently. MD Medical doctor; RN Registered nurse

and 3\%), post-ICU discharge follow-up (5\% and 7\%) and hospital mortality (3\% and $5 \%$ ) less frequently identified. The median percentage of patients reported to be readmitted per month by ICU administrators was 3 (IQR 2 to 5 ) and by ICU providers was 5 (IQR 4 to 10 ).

Figure 1 summarizes respondents' ratings of ICU discharge quality. The distribution of ratings was similar for administrators and providers. Table 4 outlines potential areas for improvement to current ICU discharge practices, with the areas of information provided to patients and families (71\% of ICU administrators and 59\% ICU providers), collaboration among hospital units (65\% and 66\%), patient or family participation during discharge (67\% and $57 \%$ ), continuity of care $(64 \%$ and $67 \%)$ and completeness of information (62\% and 64\%) being among the most frequently reported. When asked about an electronic discharge tool, the majority of respondents indicated that it could improve patient care (94\% and 85\%). Suggested elements for a tool to facilitate patient discharge from the ICU included a summary of ICU stay (33\% and 22\%), medications and medication reconciliation $(41 \%$ and $35 \%)$, and treatment and care plans ( $42 \%$ and $54 \%)$. 
TABLE 3

Respondents' reporting methods of communication with patients and families on discharge from the intensive care unit (ICU)

\begin{tabular}{lcc}
\hline & \multicolumn{2}{c}{ ICU* $^{*}$} \\
\cline { 2 - 3 } Communication & $\begin{array}{c}\text { Administrators } \\
(\mathbf{n}=\mathbf{1 1 8})\end{array}$ & $\begin{array}{c}\text { Providers } \\
(\mathbf{n}=\mathbf{7 3 7})\end{array}$ \\
\hline How information is provided to patients and families on discharge from ICU \\
Verbal communication of information & $114(99.1)$ & $591(94.9)$ \\
Written communication of information & $34(29.6)$ & $126(20.2)$ \\
Treatment plan & $24(20.9)$ & $67(10.8)$ \\
Information about new unit & $15(13.0)$ & $54(8.7)$ \\
Informed of diagnosis & $14(12.2)$ & $68(10.9)$ \\
Summary of treatment in ICU & $13(11.3)$ & $46(7.4)$ \\
\hline
\end{tabular}

Data presented as $n$ (\%). *Response rates for individual questions were $98 \%$ for administrators and $85 \%$ for providers; responses not mutually exclusive

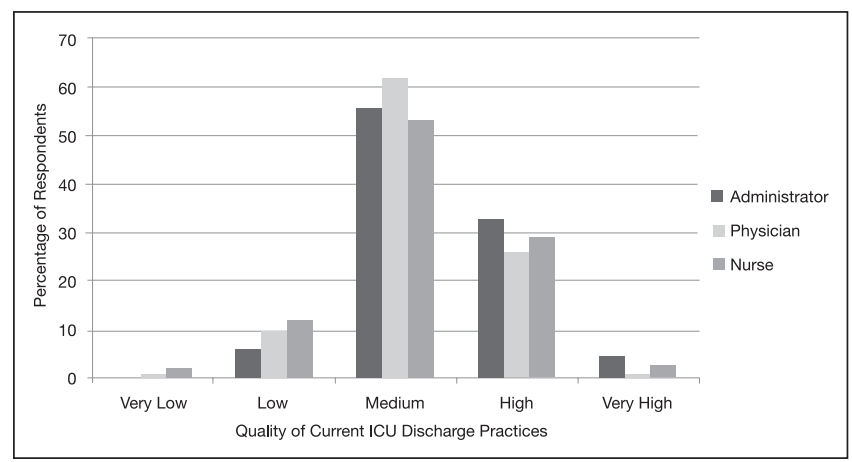

Figure 1) Respondent perceptions of the quality of care during patient discharge from the intensive care unit (ICU) according to respondent type

\section{Subgroup analyses}

Subgroup analyses of respondents according to ICU teaching status, location and number of funded beds produced similar results. ICU discharge practices, communication with patients and families, and suggested opportunities for improvement varied according to respondents' ratings of ICU discharge quality. Both ICU administrators and providers, who rated the quality of ICU discharge as high or very high compared with those who rated it as low or very low, were more likely to report that ICU discharge at their facility involved formalized nurse-to-nurse communication, formalized physician-to-physician communication, medication reconciliation, the use of standardized ICU discharge protocols and checklists, and that written communication of information was provided to patients and families (Figure 2). Conversely, ICU administrators and providers who rated the quality of ICU discharge as low or very low were more likely to identify opportunities for improvement in the ICU discharge process.

\section{DISCUSSION}

Our study provides the first description of ICU discharge practices from the perspective of Canadian ICU administrators and ICU providers in Canada, the US and the UK. The findings reveal complexity in the ICU discharge process, considerable practice variation, perception of only medium quality and several potential opportunities for improvement. Approximately one-half of respondents reported the use of a protocol or checklist during the discharge process. Most respondents rated current ICU discharge practices to be of medium quality, while only one-half reported the use of quality indicators to monitor discharge quality. Opportunities identified for improvement included the information provided to patients and families, collaboration between hospital units and continuity of care. An evidence-informed electronic discharge tool was reported as one instrument that could be used to address these opportunities for improvement.
TABLE 4

Respondents identifying opportunities for improvement in the intensive care unit (ICU) discharge process

\begin{tabular}{lcc}
\hline & \multicolumn{2}{c}{ ICU* $^{*}$} \\
\cline { 2 - 3 } Areas for improvement & \\
\cline { 2 - 3 } & $\begin{array}{c}\text { Administrators } \\
\text { (n=118) }\end{array}$ & $\begin{array}{c}\text { Providers } \\
\text { (n=737) }\end{array}$ \\
\hline Information provided to patient and family & $78(70.9)$ & $349(59.2)$ \\
Patient or family participation during & $74(67.3)$ & $334(56.6)$ \\
$\quad$ discharge & $71(64.5)$ & $387(65.6)$ \\
Collaboration among units & $70(63.6)$ & $393(66.6)$ \\
Continuity of care & $68(61.8)$ & $380(64.4)$ \\
Completeness of information & $61(55.5)$ & $294(49.8)$ \\
Timely transfer of information & $40(36.4)$ & $235(39.8)$ \\
Accuracy of information & $34(30.9)$ & $209(35.4)$ \\
Access to information & $32(29.1)$ & $150(25.4)$ \\
Duplication of information & & \\
\hline
\end{tabular}

Data presented as $n$ (\%). *The $n(\%)$ of administrator and provider respondents suggesting $\geq 1$ opportunity for improvement was 97 (93) and 590 (80), respectively. Proportions are calculated among those respondents; ${ }^{\dagger}$ Responses not mutually exclusive

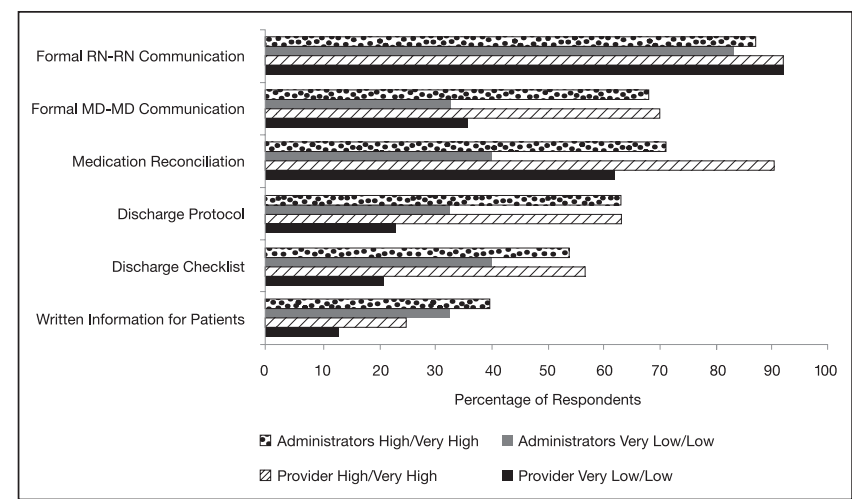

Figure 2) Intensive care unit discharge processes according to administrator and provider perceptions of the quality of current discharge practices. $\mathrm{MD}$ Medical doctor; RN Registered nurse

There are opportunities to improve the quality of patient discharge from the ICU. The limited existing literature describes variations in the models used for ICU discharge (16), and the associated risks of morbidity and mortality for discharged patients $(18,19,26)$. Heidegger et al (18) surveyed Swiss ICUs and reported that discharge practices were heterogeneous and primarily directed by individual ICU providers with limited use of written guidelines. The medical directors of these Swiss ICUs reported different discharge decisions when presented with the same clinical scenarios of patients with chronic obstructive lung disease, altered level of consciousness, trauma, sepsis and myocardial infarction being considered for discharge. Communication between providers has been documented to be infrequent, incomplete and of poor quality $(2,27)$, with $\mathrm{Li}$ et al $(27)$ reporting from an observational study that ICU and ward physicians verbally communicated in only $15 \%$ to $25 \%$ of ICU discharges. To compound matters, provider-patient communication during ICU discharge is frequently suboptimal, with the majority of patients and families indicating that more information is needed before they leave the ICU $(10,27)$. These variations and inconsistencies in discharge practices are on a backdrop of wide-ranging rates of readmission and mortality in patients following ICU discharge (28).

Implementation of evidence-informed discharge practices is the simplest and most effective way to standardize and improve the quality of ICU discharge (29). What is the optimal structure for ICU discharge? Although the current literature does not tell us, it is likely to be multidimensional. 
Our study adds to the literature in three ways. First, it highlights ongoing important practice variation in ICU discharge processes. Most notably, it appears that discharge decision making is left to individual clinicians, with approximately one-half of all Canadian ICUs using a protocol to guide the discharge process. These results are similar to those reported by Heidegger et al (18) in their survey of Swiss ICUs in 2002, and suggests that challenges to ICU discharge may be similar across different health care systems and largely unchanged by recent innovations in technology and patient care. Second, our study highlights potential opportunities for improving ICU discharge, most notably the information provided to patients and families, collaboration among hospital units and continuity of care. While there is a large body of literature involving end-of-shift (4) or end-of-service (30) patient handoffs, there is relatively little known about patient discharge between units (31). For example, in our survey, the use of formal structured communication was reported less commonly between physicians than nurses, suggesting simple concrete opportunities for improvement. Third, the respondents to our survey described their needs for implementing best practices to facilitate the discharge process. They specifically indicated that these should include a summary of the patient stay in the ICU, a reconciled list of medications and a prescribed treatment plan. Similar opportunities exist to provide patients and families with information and facilitate their engagement during the transition process.

There were limitations to the present study. The unknown denominator for the provider responses raises the question of whether the perceptions of nonrespondents were similar to respondents. While we cannot answer this, the large number of provider respondents and the good response rate from administrators, suggests that our findings are likely to represent the perspective of many ICU administrators and providers. To ensure feasibility, we restricted the study participants to ICU administrators in Canadian facilities and providers from selected professional organizations. The respondents were primarily comprised of ICU managers, nurses and physicians. Although administrator and provider responses were similar, it is possible that other stakeholders (eg, medical directors, pharmacists, physical therapists), as well as administrators and providers from other countries and professional organizations, may have different perspectives. The strengths and weaknesses of survey methodology complement other research methods. For example, survey participants reported higher proportions of verbal communication between providers during handoff than documented in observational studies. This may represent recall or social desirability biases for which survey methodology is susceptible. Conversely, our survey solicited descriptions of current ICU discharge practices and stakeholder needs from a broader and more diverse group of administrators and providers than could practically be accomplished through direct observation or other research methods.

\section{CONCLUSION}

The discharge of patients from the ICU to a hospital ward is one of the most challenging and high-risk transitions of care. Our data indicate that the ICU discharge process is multidimensional, directed by local practice patterns and associated with important practice variation. Stakeholders perceive the quality of care provided during patient discharge to be only medium. Opportunities for improvement exist with priorities including the information provided to patients and families, collaboration among hospital units and continuity of care. Development and implementation of evidence-informed ICU discharge practices may help standardize key elements of the discharge process and help health care providers deliver the highest-quality care during these transitions.

ACKNOWLEDGEMENTS: PL, JB, WG and HS contributed to the study's conception and design. JB collected and cleaned the data. PL, JB, WG and HS performed and interpreted the analyses and assisted in the successive revisions of the final manuscript. All four authors read and approved the final manuscript. The project is supported by a Seed Grant from the University of Calgary. Dr Stelfox is supported by a New Investigator Award from the Canadian Institutes of Health Research and a Population Health
Investigator Award from Alberta Innovates Health Solutions. Dr Ghali is funded by a Senior Health Scholar Award from Alberta Innovates Health Solutions. Funding sources had no role in the design of the protocol and the authors are unaware of any conflicts of interest. The authors thank Elizabeth Fradgely for helping with instrument development.

FINANCIAL SUPPORT: This project was supported by a Seed Grant from the University of Calgary, Calgary, Alberta.

CONFLICTS OF INTEREST: The authors have none to declare.

\section{APPENDIX 1}

International Survey of ICU Discharges - ICU Administrators

Dear Intensive Care Unit Stakeholder,

Attached is a short questionnaire designed to learn how intensive care units discharge patients. You are being contacted as you have extensive experience in intensive care. The survey takes less than ten minutes to complete, and your input is instrumental to this research project.

The primary aim of this research project is to gain detailed information on current ICU discharge practices, and to explore any standardized protocol that exists within Canada, United States, United Kingdom, Australia and New Zealand. You are being contacted to provide essential information about your ICU.

Discharge is broadly defined as the transfer of a patient out of an ICU. This includes discharge to home, or transition/transfer to another unit.

Discharge planning is one component of effective resource management, and is a pivotal point in a patient's transition from the ICU into other hospital facilities or into the community. Incorporating the Institute of Medicine's (IOM) aims of quality health care, the ICU discharge process should be safe, effective, efficient, and timely. However, there is little consensus on how to optimize patient safety and efficiency during ICU discharge.

Improving the discharge process could have substantial benefit in reducing readmission rates, decreasing adverse events, improving communication between hospital service providers, and reducing the use of costly ICU resources.

Your participation is voluntary and the results will be kept anonymous. The survey has full ethics approval and your participation implies consent. If you are not the appropriate person to complete this, please forward to the correct person.

If you prefer to complete this survey online, please go to:

https://www.surveymonkey.com/s/ICUDischarge

If there are any concerns or suggestions, please do not hesitate to contact: Jamie Boyd (jamboyd@ucalgary.ca)

Thank you for your participation.

\section{Background Hospital and ICU Characteristics}

This section is focused on the characteristics of your ICU and hospital.

1. Hospital name:

2. If there is more than one ICU in your hospital, list the name(s) of the ICU(s) you represent?

3. In what country is this hospital located?
$\square$ Australia
$\square$ Canada
$\square$ New Zealand
$\square$ United States
$\square$ United Kingdom
$\square$ Other (please specify)

4. What is your job title within the hospital's ICU?

5. What is the location type of your hospital? $\square$ Rural

Urban

6. What is the academic status of your hospital?

$\square$ Teaching setting

Nonteaching setting 


\section{Background ICU Characteristics}

This section is focused on the organizational characteristics of your ICU. Understanding which service providers are responsible for patients' daily care, and discharge is also explored.

7. On average, how many operational beds are in your ICU (including available nursing)?

8. Typically, within your ICU how many patients will a nurse be assigned to during the day (nurse to patient ratio)?
$\square$ 1-2 patients
$\square$ 3-4 patients
$\square 5$ or more patients

9. Typically, what population(s) is admitted in your hospital's ICU? (Select all that apply)
$\square$ Surgical
$\square$ Trauma
$\square$ Medical
$\square$ Neurological
$\square$ Neonatal
$\square$ Pediatric
$\square$ Cardiovascular or Cardiac
$\square$ Other (Please specify):

10. Does your ICU provide ventilation support to acute ill patients? $\square$ Yes

$\square$ No

\section{Health Professionals and Collaboration in ICU}

This section explores the professional team within your ICU and the collaboration between ICU and general units. Questions will focus on your ICU discharge process and the communication between discharging physicians and receiving health services.

11. Typically, are ICU daily rounds directed by an intensivist?

$\square$ Yes

$\square$ No

12. Typically, which of the following health professionals are involved in daily rounds? (Select all that apply)

$\square$ Medical doctor (MD)

$\square$ Registered nurse (RN)

$\square$ Nurse Clinician

$\square$ ICU Resident (Doctor in training)

$\square$ ICU Fellow (Doctor training to be an intensivist)

$\square$ Respiratory Therapist

$\square$ Occupational Therapist

$\square$ Pharmacist

$\square$ Social Worker

$\square$ Dietician

$\square$ Other (please specify):

13. Typically, what roles or decisions do ICU discharging physicians and the receiving service physician have in discharging patients? (If both units perform the role, please select both)

Deciding time of discharge

$\square$ ICU Physician $\square$ Receiving Service Physician $\quad \square$ Neither

Assessing safety of discharge

$\square$ ICU Physician $\square$ Receiving Service Physician $\quad \square$ Neither

Deciding the appropriate receiving service for the patient

$\square$ ICU Physician $\square$ Receiving Service Physician $\square$ Neither

Ensuring transfer of information

$\square$ ICU Physician $\square$ Receiving Service Physician $\square$ Neither Are there other roles or decisions essential to the discharge process (for ICU physicians or receiving service physician)?

14. Is there a dedicated team or individual that transitions and monitors patients during discharge from the ICU to other hospital services?

$\square$ No

$\square$ Yes (please provide name of team or type of individual)
15. Please rank the following health services by the proportion of ICU patients discharged to that respective receiving health service $(1=$ most discharges, $6=$ least discharges $)$

Primary care, or family doctor

Surgical specialty

Medical specialty (including psychiatry, or internal medicine)

Discharged to another hospital

Discharged to home

Other

\section{Tools and Communication for ICU Discharge}

This page contains questions focused on the current ICU discharge process within your facility, and what tools are used to facilitate a seamless discharge.

16. Typically, what communication is included in the discharge process? (Select all that apply)

$\square$ Formalized communication between discharging nurse and receiving nurse

$\square$ Informal communication between discharging nurse and receiving nurse

$\square$ Formalized communication between discharging physician and receiving physician

$\square$ Informal communication between discharging physician and receiving physician

$\square$ Other (please specify)

17. Please select the frequency at each mode of communication is used during the discharge process.

Face to face

$$
\square \text { Very Frequently } \square \text { Sometimes } \square \text { Very Rarely }
$$

Telephone

$\square$ Very Frequently $\square$ Sometimes $\square$ Very Rarely

Email or other electronic communication

$\square$ Very Frequently $\square$ Sometimes $\square$ Very Rarely

Paper

$\square$ Very Frequently $\square$ Sometimes $\square$ Very Rarely

18. Currently, what information is given to the receiving health service regarding the patient?

$\square$ Medical history

$\square$ Investigations and tests

$\square$ Diagnosis

$\square$ Prescriptions

$\square$ Treatment plan

$\square$ Other (please specify)

19. Is there a standardized ICU checklist or protocol completed before a patient is discharged to another unit or health service?

$\square$ Yes

$\square$ No

20. Currently, are any of the following components used in ICU discharge? (Select all that apply)

$\square$ Patient summary (including dictated information)

$\square$ Medication reconciliation

$\square$ Standardized discharge checklist

$\square$ Electronic discharge tool

$\square$ Use of a patient assessment score to guide discharge decision making (ex. Swift score). Please enter the patient assessment score if used.

21. Are there any other tools used to facilitate a patient's discharge from ICU services?

22. Is there an electronic system currently used for patient care within the ICU?

$\square$ Yes

$\square$ No

23. Does this electronic system facilitate ICU patient discharge? $\square$ Yes

$\square$ No 
Tools and Communication for ICU Discharge

In order to facilitate patient-centered care, understanding what information is provided to patients and family members regarding their discharge from ICU services is essential.

24. Typically upon discharge from ICU services to another health service or unit, how is information given to patients or family members? (Select all that apply)

$\square$ Verbal communication of information

$\square$ Written communication of information

$\square$ No information given

25. Typically upon discharge from ICU services to the patient's home, is written information given to the patient or family members? (Select all that apply)

$\square$ Verbal communication of information

$\square$ Written communication of information

$\square$ No information given

26. Is any of the following personalized written information given to patients or family members? (Please select all that apply)

$\square$ Informed of diagnosis (ex. "You have this medical condition")

$\square$ Summary of treatment in ICU (ex. "You received this treatment in ICU")

$\square$ Treatment plan (ex. "You will need this treatment")

$\square$ Information about the hospital services on new unit (ex. "You can have two visitors")

$\square$ No personalized written information given

$\square$ Other information. Please specify written information.

\section{Quality of Discharge Process and Experience}

This section is focused on your perception of the current ICU discharge process within your facility.

27. What is the estimated average number of ICU discharges in one week?

28. Please estimate the percentage of patients discharged from ICU and then readmitted before being discharged home (ex. 10\% of patients are readmitted/ in hospital ICU readmission rate).

$\square$ Cannot provide an estimated percentage of readmissions

$\square$ Estimated percentage of readmissions

29. Are there any quality indicators used within your ICU to evaluate the current discharge process (ex. readmission rates)?

$\square$ No

$\square$ Yes. Please specify the quality indicators used.

30. In your opinion, what is the quality of the current discharge process?

$\square$ Very low quality

$\square$ Low quality

$\square$ Medium quality

$\square$ High quality

$\square$ Very high quality

31. In your opinion, is there an opportunity to improve any of the following components of the current ICU discharge process?

(Please select all that apply)

$\square$ Timely transfer of information

$\square$ Completeness of information

$\square$ Accuracy of information

$\square$ Access to information

$\square$ Duplication of information

$\square$ Continuity of care

$\square$ Collaboration between units (ICU and receiving health services)

$\square$ Patient or family role and participation during ICU discharge

$\square$ Information provided to patient and family

$\square$ Other (please specify)

32. In your opinion, could an electronic discharge tool be beneficial for ICU service providers?

$\square$ Yes

$\square$ No
33. In your opinion, what should be included in an electronic discharge tool in order to facilitate efficient, safe, timely, and patientcentered discharge from ICU?

\section{Conclusion}

Thank you for completing this survey. This study will provide the foundational information needed to develop a standardized ICU discharge process and electronic tool.

The research team would like to invite you to participate in a short telephone interview. This additional telephone interview will explore the perspectives of ICU service providers regarding the quality and barriers to ICU discharge, to explore specific needs and expectations surrounding ICU discharge, and identify key intervention points appropriate for a standardized ICU discharge protocol.

34. We would like to briefly interview you to learn more about your opinion on ICU discharge tools. What is the best way to contact you to schedule a short telephone interview (email address, telephone number, or other)?

35. If you are not the best person in your ICU facility for this interview, could you direct us to a person who would be more appropriate for us to contact?

Thank you.

\section{APPENDIX 2}

International Survey of ICU Discharges - ICU Providers

Dear Intensive Care Unit Stakeholder,

Attached is a short questionnaire designed to learn how intensive care units discharge patients. You are being contacted as you have extensive experience in intensive care. The survey takes less than ten minutes to complete, and your input is instrumental to this research project.

The primary aim of this research project is to gain detailed information on current ICU discharge practices, and to explore any standardized protocol that exists within Canada, United States, United Kingdom, Australia and New Zealand. You are being contacted to provide essential information about your experience with ICU discharges.

Discharge is broadly defined as the transfer of a patient out of an ICU. This includes discharge to home, or transition/transfer to another unit.

Discharge planning is one component of effective resource management, and is a pivotal point in a patient's transition from the ICU into other hospital facilities or into the community. Incorporating the Institute of Medicine's (IOM) aims of quality health care, the ICU discharge process should be safe, effective, efficient, and timely. However, there is little consensus on how to optimize patient safety and efficiency during ICU discharge.

Improving the discharge process could have substantial benefit in reducing readmission rates, decreasing adverse events, improving communication between hospital service providers, and reducing the use of costly ICU resources.

Your participation is voluntary and the results will be kept anonymous. The survey has full ethics approval and your participation implies consent.

If there are any concerns or suggestions, please do not hesitate to contact: Jamie Boyd (jamboyd@ucalgary.ca)

Thank you for your participation.

Background Hospital and ICU Characteristics

This section is focused on the characteristics of your ICU and hospital.

1. In what country is this hospital located?
$\square$ Australia
$\square$ Canada
$\square$ New Zealand
$\square$ United States
$\square$ United Kingdom
$\square$ Other (please specify) 
2. What is your job title within the hospital's ICU?

3. What is the location type of your hospital? $\square$ Rural

$\square$ Urban

4. What is the academic status of your hospital?

$\square$ Teaching setting

$\square$ Nonteaching setting

5. On average, how many operational beds are in your ICU (including available nursing)?

6. Does your ICU provide ventilation support to acute ill patients? $\square$ Yes

$\square$ No

7. Typically, what population(s) is admitted in your hospital's ICU? (Select all that apply)

$\square$ Surgical

$\square$ Trauma

$\square$ Medical

$\square$ Neurological

$\square$ Neonatal

$\square$ Pediatric

$\square$ Cardiovascular or Cardiac

$\square$ Other (Please specify):

\section{Health Professionals and Collaboration in ICU}

This section explores the professional team within your ICU and the collaboration between ICU and general units. Questions will focus on your ICU discharge process and the communication between discharging physicians and receiving health services.

8. Typically, which of the following health professionals are involved in daily rounds? (Select all that apply)

$\square$ Medical doctor (MD)

$\square$ Registered nurse (RN)

$\square$ Nurse Clinician

$\square$ ICU Resident (Doctor in training)

$\square$ ICU Fellow (Doctor training to be an intensivist)

$\square$ Respiratory Therapist

$\square$ Occupational Therapist

$\square$ Pharmacist

$\square$ Social Worker

$\square$ Dietician

$\square$ Other (Please specify):

9. Typically, are ICU daily rounds directed by an intensivist?

$\square$ Yes

$\square$ No

10. Typically, what roles or decisions do ICU discharging physicians and the receiving service physician have in discharging patients? (If both units perform the role, please select both)

Deciding time of discharge

$\square$ ICU Physician $\quad \square$ Receiving Service Physician $\quad \square$ Neither Assessing safety of discharge

$\square$ ICU Physician $\square$ Receiving Service Physician $\quad \square$ Neither

Deciding the appropriate receiving service for the patient

$\square$ ICU Physician $\square$ Receiving Service Physician $\quad \square$ Neither

Ensuring transfer of information

$\square$ ICU Physician $\square$ Receiving Service Physician $\square$ Neither Are there other roles or decisions essential to the discharge process (for ICU physicians or receiving service physician)?

11. Is there a dedicated team or individual that transitions and monitors patients during discharge from the ICU to other hospital services?

$\square$ No

$\square$ Yes (please provide name of team or type of individual)
12. Please rank the following health services by the proportion of ICU patients discharged to that respective receiving health service ( $1=$ most discharges, $6=$ least discharges $)$. Primary care, or family doctor Surgical specialty Medical specialty (including psychiatry, or internal medicine) Discharged to another hospital Discharged to home Other

\section{Tools and Communication for ICU Discharge}

This page contains questions focused on the current ICU discharge process within your facility, and what tools are used to facilitate a seamless discharge.

13. Is there a standardized ICU checklist or protocol completed before a patient is discharged to another unit or health service?

$\square$ Yes

$\square$ No

14. Typically, what communication is included in the discharge process? (Select all that apply)

$\square$ Formalized communication between discharging nurse and receiving nurse

$\square$ Informal communication between discharging nurse and receiving nurse

$\square$ Formalized communication between discharging physician and receiving physician

$\square$ Informal communication between discharging physician and receiving physician

$\square$ Other (please specify)

15. Please select the frequency at each mode of communication is used during the discharge process.

Face to face

$$
\begin{array}{cc}
\square \text { Very Frequently } \quad \square \text { Sometimes } & \square \text { Very Rarely } \\
\text { Telephone } & \\
\square \text { Very Frequently } \quad \square \text { Sometimes } & \square \text { Very Rarely } \\
\text { Email or other electronic communication } & \\
\square \text { Very Frequently } \quad \square \text { Sometimes } & \square \text { Very Rarely } \\
\text { Paper } & \\
\square \text { Very Frequently } \quad \square \text { Sometimes } & \square \text { Very Rarely }
\end{array}
$$

16. Currently, what information is given to the receiving health service regarding the patient?

$\square$ Medical history

$\square$ Investigations and tests

$\square$ Diagnosis

$\square$ Prescriptions

$\square$ Treatment plan

$\square$ Other (Please specify):

17. Currently, are any of the following components used in ICU discharge? (Select all that apply)

$\square$ Patient summary (including dictated information)

$\square$ Medication reconciliation

$\square$ Standardized discharge checklist

$\square$ Electronic discharge tool

$\square$ Use of a patient assessment score to guide discharge decision making (ex. Swift score). Please enter the patient assessment score if used.

18. Are there any other tools used to facilitate a patient's discharge from ICU services?

19. Is there an electronic system currently used for patient care within the ICU?

$\square$ Yes

$\square$ No

20. Does this electronic system facilitate ICU patient discharge? $\square$ Yes

$\square$ No 
Tools and Communication for ICU Discharge

In order to facilitate patient-centered care, understanding what information is provided to patients and family members regarding their discharge from ICU services is essential.

21. Typically upon discharge from ICU services to another health service or unit, how is information given to patients or family members? (Select all that apply)

$\square$ Verbal communication of information

$\square$ Written communication of information

$\square$ No information given

22. Typically upon discharge from ICU services to the patient's home, is written information given to the patient or family members? (Select all that apply)

$\square$ Verbal communication of information

$\square$ Written communication of information

$\square$ No information given

23. Is any of the following personalized written information given to patients or family members? (Please select all that apply)

$\square$ Informed of diagnosis (ex. "You have this medical condition")

$\square$ Summary of treatment in ICU (ex. "You received this treatment in ICU")

$\square$ Treatment plan (ex. "You will need this treatment")

$\square$ Information about the hospital services on new unit (ex. "You can have two visitors")

$\square$ No personalized written information given

$\square$ Other information. Please specify written information.

Quality of Discharge Process and Experience

This section is focused on your perception of the current ICU discharge process within your facility.

24. In your opinion, what is the quality of the current discharge process?

$\square$ Very low quality

$\square$ Low quality

$\square$ Medium quality

$\square$ High quality

$\square$ Very high quality

25. In your opinion, is there an opportunity to improve any of the following components of the current ICU discharge process? (Please select all that apply)

$\square$ Timely transfer of information

$\square$ Completeness of information

$\square$ Accuracy of information

$\square$ Access to information

$\square$ Duplication of information

$\square$ Continuity of care

$\square$ Collaboration between units (ICU and receiving health services)

$\square$ Patient or family role and participation during ICU discharge

$\square$ Information provided to patient and family

$\square$ Other (Please specify):

26. In your opinion, could an electronic discharge tool be beneficial for ICU service providers?

$\square$ Yes

$\square$ No

27. In your opinion, what should be included in an electronic discharge tool in order to facilitate efficient, safe, timely, and patient-centered discharge from ICU?

28. Are there any quality indicators used within your ICU to evaluate the current discharge process (ex. readmission rates)?

$\square$ No

$\square$ Yes. Please specify the quality indicators used
29. What is the estimated average number of ICU discharges in one week?

30. Please estimate the percentage of patients discharged from ICU and then readmitted before being discharged home (ex. 10\% of patients are readmitted/ in hospital ICU readmission rate).

$\square$ Cannot provide an estimated percentage of readmissions

$\square$ Estimated percentage of readmissions

\section{Conclusion}

Thank you for completing this survey. This study will provide the foundational information needed to develop a standardized ICU discharge process and electronic tool.

The research team would like to invite you to participate in a short telephone interview. This additional telephone interview will explore the perspectives of ICU service providers regarding the quality and barriers to ICU discharge, to explore specific needs and expectations surrounding ICU discharge, and identify key intervention points appropriate for a standardized ICU discharge protocol.

31. We would like to briefly interview you to learn more about your opinion on ICU discharge tools. What is the best way to contact you to schedule a short telephone interview (email address, telephone number, or other)?

32. If you are not the best person in your ICU facility for this interview, could you direct us to a person who would be more appropriate for us to contact?

Thank you.

\section{REFERENCES}

1. Institute of Medicine. To Err is Human. Washington DC, National Academy Press, 1999.

2. Ong MS, Coiera E. A systematic review of failures in handoff communication during intrahospital transfers. Jt Comm J Qual Patient Saf 2011;37:274-84.

3. Accreditation Canada. Required organizational practices. <www. accreditation.ca/knowledge-exchange/patient-safety/requiredorganizational-practices/> (Accessed September 12, 2012).

4. Solet DJ, Norvell JM, Rutan GH, Frankel RM. Lost in translation: Challenges and opportunities in physician-to-physician communication during patient handoffs. Acad Med 2005;80:1094-9.

5. Arora V, Johnson J, Lovinger D, Humphrey HJ, Meltzer DO. Communication failures in patient sign-out and suggestions for improvement: A critical incident analysis. Qual Saf Health Care 2005;14:401-7.

6. Charles C, Gauld M, Chambers L, et al. How was your hospital stay? Patients' reports about their care in Canadian hospitals. CMAJ 1994;150:1813-22.

7. Bell CM, Brener SS, Gunraj N, et al. Association of ICU or hospital admission with unintentional discontinuation of medications for chronic diseases. JAMA 2011;306:840-7.

8. Forster AJ, Murff HJ, Peterson JF, Gandhi TK, Bates DW. The incidence and severity of adverse events affecting patients after discharge from the hospital. Ann Intern Med 2003;138:161-7.

9. National Transitions of Care Coalition. Improving transitions of care. < www.ntocc.org/Portals/0/PDF/Resources/PolicyPaper.pdf> (Accessed October 10, 2012).

10. Forsberg A, Lindgren E, Engström $\AA$. Being transferred from an intensive care unit to a ward: Searching for the known in the unknown. Int J Nurs Pract 2011;17:110-6.

11. Halasyamani L, Kripaliani S, Coleman E, et al. Transition of care for hospitalized elderly patients - development of a discharge checklist for hospitalists. J Hosp Med 2006;1:354-60.

12. Camire E, Moyen E, Stelfox HT. Medication errors in critical care: Risk factors, prevention and disclosure. CMAJ 2009;180:936-43.

13. Rozich JD, Howard RJ, Justeson JM, et al. Standardization as a mechanism to improve safety in health care. Jt Comm J Qual Patient Saf 2004;30:5-14.

14. Using medication reconciliation to prevent errors. Sentinel Event Alert 2006:1-4. 
15. Pronovost $\mathrm{P}$, Weast $\mathrm{B}$, Schwarz $\mathrm{M}$, et al. Medication reconciliation: A practical tool to reduce the risk of medication errors. J Crit Care 2003;18:201-5.

16. Watts R, Pierson J, Gardner H. Coordination of the discharge process planning in critical care. J Clin Nurs 2005;21:39-46.

17. Rosenberg AL, Watts C. Patients readmitted to ICUs: A systematic review of risk factors and outcomes. CHEST 2000;118:492-502.

18. Heidegger C, Treggiari M, Romand J, Swiss ICU Network. A nationwide survey of intensive care discharge practice. Intens Care Med 2005;31:1676-82.

19. Kripalani S, Jackson AT, Schnipper JL, Coleman EA. Promoting effective transitions of care at hospital discharge: A review of key issues for hospitalists. J Hosp Med 2007;2:314-23.

20. Society for Critical Care Medicine. Practicing CCM. <www.sccm. org/AboutSCCM/Public\%20Relations/Media_Kit/Pages/Practicing_ CCM.aspx> (Accessed March 23, 2012).

21. Canadian Association of Critical Care Nurses. < caccn.ca/> (Accessed October 12, 2013)

22. Society for Critical Care Medicine. <www.sccm.org/Pages/default. aspx $>$ (Accessed October 12, 2013).

23. The Intensive Care Society. <www.ics.ac.uk> (Accessed October 12, 2013).

24. Burns KE, Duffett M, Kho ME, et al. A guide for the design and conduct of self-administered surveys of clinicians. CMAJ 2008;179:245-52.
25. SPSS Inc: SPSS Statistics for Windows, Version 17.0. Chicago: SPSS Inc; 2008.

26. Brown SE, Ratcliffe SJ, Kahn JM, Halpern, SD. The epidemiology of intensive care unit readmissions in the United States. Am J Respir Crit Care Med 2012;185:955-64.

27. Li P, Stelfox HT, Ghali WA. A prospective observational study of physician handoff for intensive-care-unit-to-ward patient transfers. Am J Med 2011;124:860-7.

28. Hosein FS, Bobrovitz N, Berthelot S, et al. A systematic review of tools for predicting severe adverse events following patient discharge from intensive care units. Crit Care 2013;17:R102.

29. Guidelines for intensive care unit admission, discharge, and triage. Task Force of the American College of Critical Care Medicine, Society of Critical Care Medicine. Crit Care Med 1999;27:633-8.

30. Horwitz LI, Moin T, Krumholz HM, Wang L, Bradley EH. What are covering doctors told about their patients? Analysis of sign-out among internal medicine house staff. Qual Saf Health Care 2009; 18:248-55.

31. Horwitz LI, Meredith T, Schuur JD, et al. Dropping the baton: A qualitative analysis of failures during the transition from emergency department to inpatient care. Ann Emerg Med 2009;53:701-10.e704. 


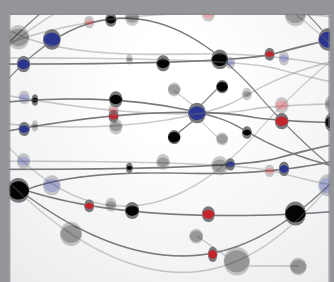

The Scientific World Journal
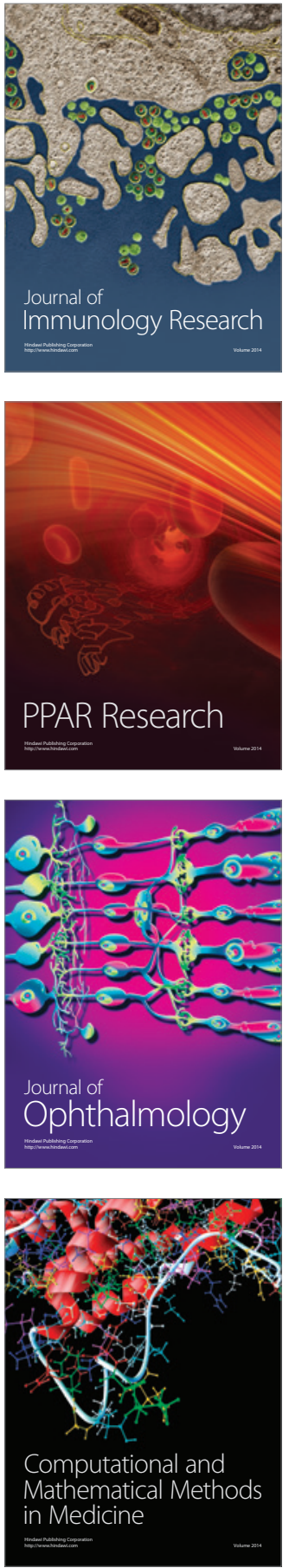

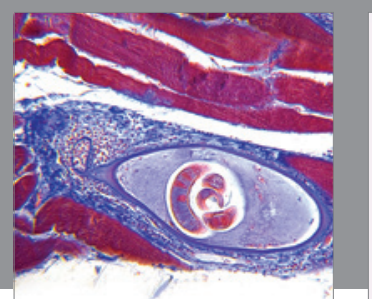

Gastroenterology Research and Practice

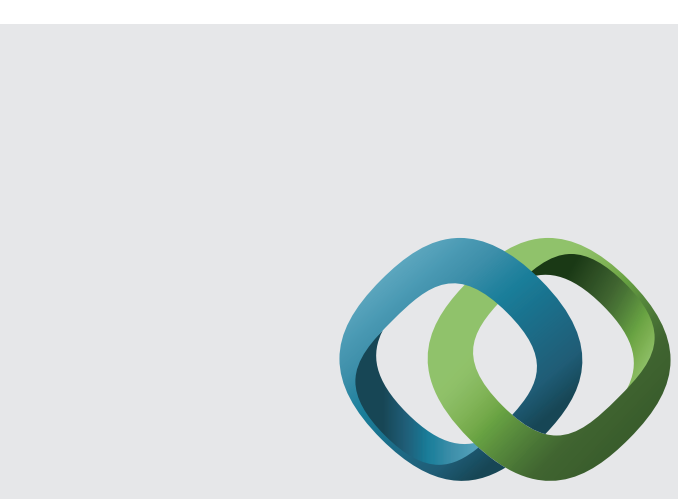

\section{Hindawi}

Submit your manuscripts at

http://www.hindawi.com
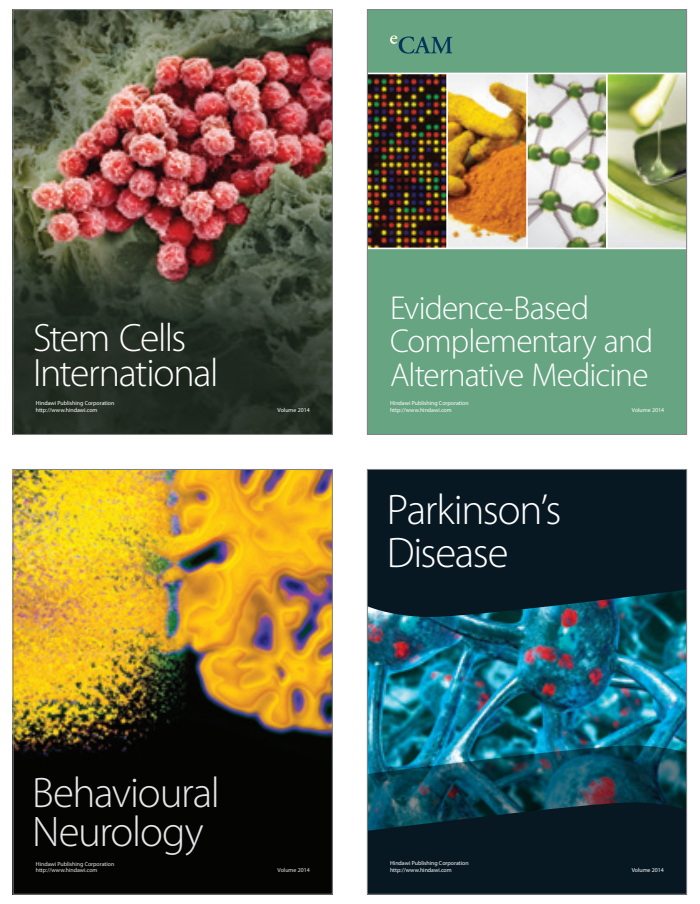
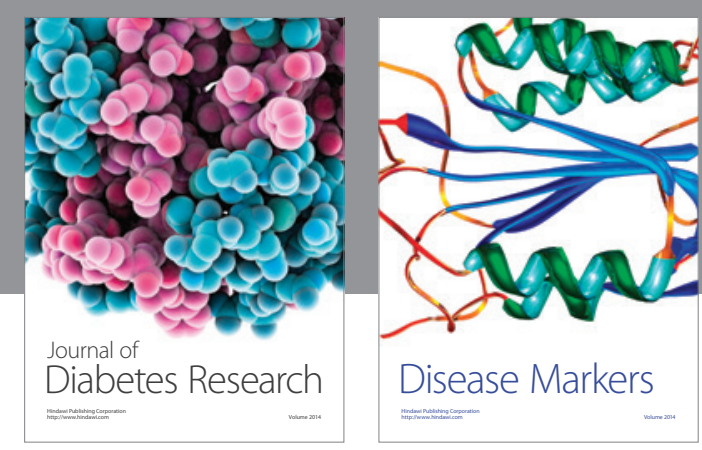

Disease Markers
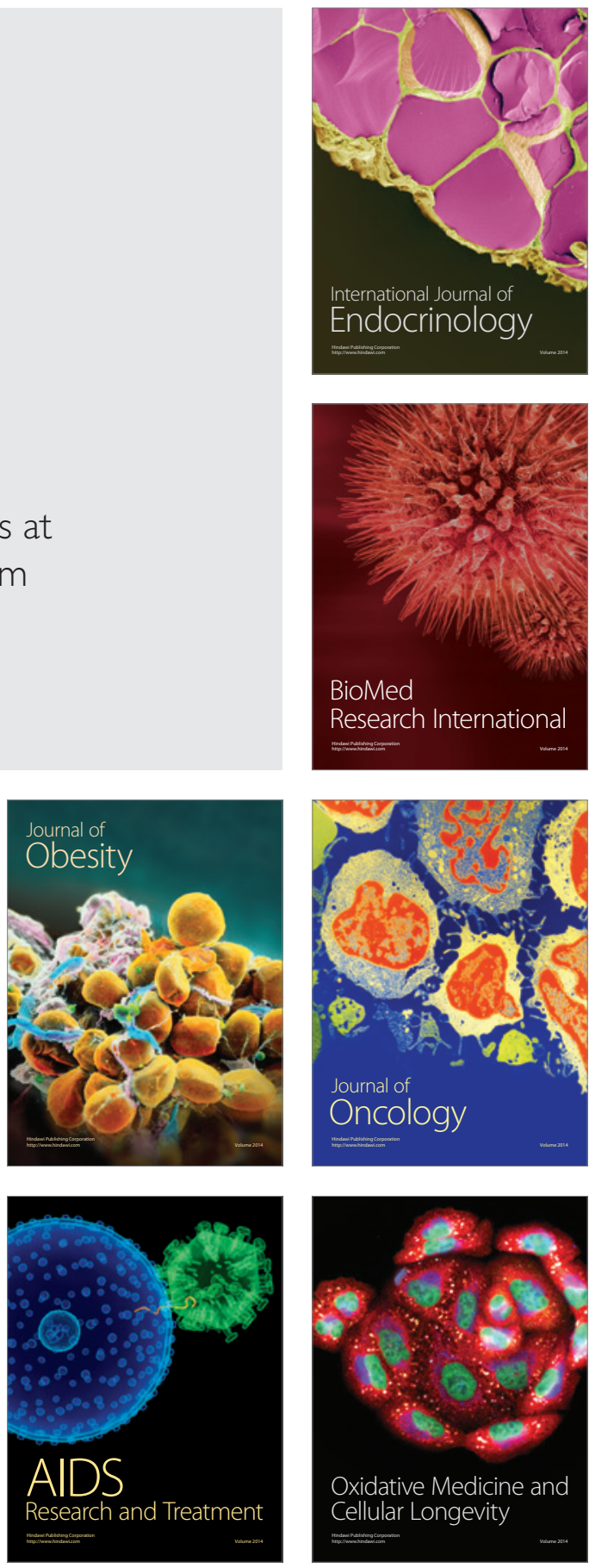